\title{
La licencia administrativa para la tenencia de perros potencialmente peligrosos. ¿Obligación exclusiva del propietario ${ }^{1}$
}

\section{María González Lacabex ${ }^{2}$}

"Mire, me han puesto una multa por pasear a nuestro pitbull, supuestamente por no tener la licencia correspondiente. Pero sí tenemos licencia, lo que pasa es que está a nombre de mi hijo, porque en realidad el perro es suyo..." La consulta anterior hace referencia a una duda bastante habitual en relación con la obligación administrativa de poseer una licencia para la tenencia de perros clasificados legalmente como potencialmente peligrosos (PPP): Esta obligación, ¿corresponde únicamente al propietario? Si el perro convive y es atendido por varios miembros de la familia, ¿es suficiente con que sólo uno de ellos, quien conste como titular del animal, acredite su capacidad para tenerlo? ¿Puede alguien que no tiene un perro de estas características (o incluso, que no tiene perro) obtener este tipo de licencia?

La Ley 50/1999, de 23 de diciembre, sobre el Régimen Jurídico de la Tenencia de Animales Potencialmente Peligrosos ${ }^{3}$, y el Real Decreto $287 / 2002^{4}$ que la desarrolla (modificado a su vez por el Real Decreto 1570/20075), sujetan la tenencia de cualesquiera animales clasificados como potencialmente peligrosos a la previa obtención de una licencia administrativa otorgada por el Ayuntamiento del municipio de residencia del solicitante. Esta licencia sólo podrán obtenerla las personas mayores

1 Vid. González Lacabex, María: Licencias PPP. ¿Sólo para el propietario? Publicado en: http://animalexabogados.com/blog/ Noviembre 2014.

\footnotetext{
${ }^{2}$ Abogada. Máster en Derecho del Medio Ambiente. Especialista Universitaria en Desarrollo Sostenible y Agenda 21 Local. Postgrado Animales, Derecho y Sociedad (UAB, 2011). Miembro del SGR Grupo de Investigación Animales, Derecho y Sociedad de la UAB. Fundadora de ANIMALEX, despacho dedicado exclusivamente a Derecho Animal.

${ }^{3}$ http://www.derechoanimal.info/bbdd/Documentos/205.pdf

${ }^{4}$ http://www.derechoanimal.info/bbdd/Documentos/211.pdf

${ }^{5}$ http://www.derechoanimal.info/bbdd/Documentos/213.pdf
} 
de edad que no estén incapacitadas; carezcan de antecedentes penales; no hayan sido sancionadas por infracciones graves o muy graves en esta materia; aporten un certificado de capacidad física y aptitud psicológica; y suscriban un seguro de responsabilidad civil por los daños a terceros que pudieran causar sus animales ${ }^{6}$.

La Ley no detalla, de manera explícita, si dicha obligación corresponde únicamente al propietario del perro o si también afecta a cualquier poseedor, sino que se refiere con carácter general a su "tenencia". A partir de aquí, el tenor literal de la norma induce a cierta confusión:

- Por un lado, el hecho de que entre los requisitos necesarios para su obtención se incluya el seguro de responsabilidad civil (obligación del propietario) parece presuponer la existencia efectiva de un animal a cargo del solicitante de licencia. Asimismo, el Real Decreto 287/2002, en su desarrollo de las previsiones de la Ley 50/1999, indica que "no podrán ser titulares de animales potencialmente peligrosos las personas que carezcan de las condiciones físicas..." (artículo 4.1).

- Sin embargo, al mismo tiempo este Real Decreto dispone que "la presencia de animales potencialmente peligrosos en lugares o espacios públicos exigirá que la persona que los conduzca y controle lleve consigo la licencia administrativa a que se refiere el artículo 3 de este Real Decreto, así como certificación acreditativa de la inscripción del animal en el Registro Municipal de animales potencialmente peligrosos" (artículo 8). Entonces, ¿estamos ante una licencia que sólo corresponde obtener al titular de estos animales, o es exigible también la misma a "cualquiera que los conduzca y controle?".

Lo cierto es que no existe obligación legal alguna de que quien conduzca un perro sea su propietario; nada impide que sea otra persona la que lo saque a pasear, o lo custodie durante un tiempo. Si esta persona no coincide con el propietario del perro, ¿significa esto que debe llevar consigo su propia licencia administrativa, o la del titular

\footnotetext{
${ }^{6}$ Vid. en dA webcenter: ¿Qué documentación es necesaria para poder tener un animal potencialmente peligroso? http://www.derechoanimal.info/esp/page/1571/¿que-documentacion-es-necesaria-para-podertener-un-animal-potencialmente-peligroso-
} 
del animal? Lo segundo no parece muy lógico, aunque la norma como hemos visto tampoco es clara al respecto. Ello suele dar lugar a situaciones de confusión en los registros administrativos de los ayuntamientos, en los que resulta habitual que el funcionario correspondiente insista en exigir en todo caso al solicitante de esta licencia el seguro de responsabilidad civil y la inscripción del animal en el registro de animales potencialmente peligrosos. Documentación que, evidentemente, no podrá aportar quien no tiene un perro de estas características a su nombre.

Ante una legislación estatal que no deja muy claro este extremo, nos encontramos con 17 leyes promulgadas por los parlamentos autonómicos y cientos de ordenanzas aprobadas por ayuntamientos que, en ejercicio de sus competencias de desarrollo, se limitan en la mayor parte de los casos a reproducir las disposiciones de la Ley 50/1999 y el Real Decreto 287/2002. Algunas de estas normativas, como la Ley del Principado de Asturias 13/2002, de 23 de diciembre, de Asturias ${ }^{7}$, inciden aún más en esta confusión, al disponer expresamente que "para la obtención de licencia de animales potencialmente peligrosos serán precisos los siguientes requisitos, que deberán mantenerse durante toda la vida del animal" (artículo 24), y entre los cuales se encuentra "haber formalizado un seguro de responsabilidad civil por daños a terceros que puedan ser causados por sus animales" (artículo 23.2.d). De lo anterior se desprende que, con arreglo a esta legislación, la licencia para la tenencia de PPP está siempre vinculada a la tenencia-propiedad de un animal concreto.

Especialmente clarificador resulta, por el contrario, el Decreto 30/2003, de 13 de marzo, de la Comunidad de Madrid $^{8}$, que disipa toda duda al respecto al disponer

\footnotetext{
${ }^{7}$ Ley del Principado de Asturias 13/2002, de 23 de diciembre, de tenencia, protección y derechos de los animales. http://www.derechoanimal.info/bbdd/Documentos/229.pdf

${ }^{8}$ Decreto 30/2003, de 13 de marzo, de la Comunidad de Madrid por el que se aplica en la Comunidad de Madrid el R.D. 287/2002 y se crean los registros de perros potencialmente peligrosos. http://www.derechoanimal.info/bbdd/Documentos/438.pdf
} 
que: "Todas aquellas personas que manejen, incluso para el paseo o esparcimiento, de forma habitual, continua o circunstancial, perros definidos como potencialmente peligrosos deberán estar igualmente en posesión de la correspondiente licencia" (artículo 3.1). Asimismo: "Aquellas personas que, sin ser propietarios ni poseedores o usuarios en propio interés, se dediquen por cuenta de otros al cuidado, mantenimiento, educación o entrenamiento de perros potencialmente peligrosos, deberán estar igualmente en posesión de la licencia" (artículo 4).

Por su parte, en Euskadi, el Decreto 101/2004, de 1 de junio, que regula la tenencia de animales de la especie canina ${ }^{9}$ señala expresamente que la obligación de suscribir un seguro de responsabilidad civil corresponde en exclusiva a los propietarios (artículo 12), pero extiende el resto de obligaciones relativas a la conducción y control de PPP a cualquier persona, es decir, el "tenedor" o "poseedor" del animal, el cual, como sabemos, no tiene por qué coincidir necesariamente con su propietario legal (artículo 13). En esta Comunidad debe tener esta licencia, a su nombre, toda persona que se responsabilice de un PPP en un espacio público. Y así se ha especificado, para mayor claridad, desde el propio Registro autonómico de identificación de animales (REGIA): En una casa en la que haya un PPP, además del propietario, deberán tener licencia todos los miembros de la familia que vayan a sacarlo a pasear.

En conclusión, parece que la lógica se inclina del lado de las normativas que exigen la licencia para cualquiera que maneje esos animales. $Y$ es que el permiso para la tenencia de PPP es una licencia personal que habilita a su titular, previa acreditación de su capacidad y aptitud para ello, para poder custodiar en un momento determinado un perro de estas características, sin necesidad de ser propietario del mismo. Por este motivo, sin perjuicio de que en cada lugar debamos estar a lo que expresamente prevean la legislación autonómica y ordenanza municipal aplicables, razones de

\footnotetext{
${ }^{9}$ Decreto 101/2004, de 1 de junio, que regula la tenencia de animales de la especie canina en la Comunidad Autónoma Vasca. http://www.derechoanimal.info/bbdd/Documentos/702.pdf
} 


\section{dA derecho ANIMAL la web center de los animales con derecho}

seguridad jurídica deben llevarnos siempre a interpretar esta obligación en el sentido apuntado:

Cualquier persona interesada que cumpla los requisitos de mayoría de edad, capacidad, carencia de antecedentes penales o de sanciones administrativas por esta misma materia, y aptitud física y psicológica, está en su derecho - Y OBLIGACIÓN, si va a manejar PPP - de solicitar y obtener la referida licencia, sin necesidad de acreditar la propiedad por su parte de un animal de estas características, ni ninguna de las obligaciones (registrales y de aseguramiento), que son exclusivamente exigibles a los propietarios. 